\title{
Synthesis of Azidothymidine-Bound Sulfated Alkyl Oligosaccharides and Their Inhibitory Effects on AIDS Virus Infection In Vitro
}

\author{
Ying Gao, Kaname Katsuraya, Yutaro Kaneko,* Toru Mimura,* \\ Hideki NaKashima, ${ }^{* *}$ and Toshiyuki $\mathrm{URYU}^{\dagger}$ \\ Institute of Industrial Science, The University of Tokyo, Roppongi, Minato-ku, Tokyo 106, Japan \\ * Ajinomoto Co., Kyobashi, Chuo-ku, Tokyo 104, Japan \\ ** Dental School, Kagoshima University, Sakuragaoka, Kagoshima 890, Japan
}

(Received August 28, 1997)

\begin{abstract}
In order to sustain an acquired immunodeficiency syndrome (AIDS) drug azidothymidine (AZT) in high level in the blood, novel AZT prodrugs, i.e., AZT-bound sulfated laminaripentaose and AZT-bound sulfated alkyl laminaripentaosides, were synthesized. AZT was introduced into the backbone of laminaripentaose and alkyl laminaripentaoside through biodegradable ester bond to give AZT-bound laminaripentaose and AZT-bound alkyl laminaripentaoside, respectively. Subsequently, they were sulfated with $\mathrm{SO}_{3}$-pyridine complex to produce AZT-bound sulfated laminaripentaose and AZT-bound sulfated alkyl laminaripentaoside. Their anti-Human Immunodeficiency Virus (HIV) activities were assayed in vitro by use of the 3-(4,5-dimethylthiazol-2-yl)-2,5-diphenyltetrazolium (MTT) method. It was revealed that AZT-bound sulfated laminaripentaose exhibited much higher anti-HIV activity $\left(\mathrm{EC}_{50}=0.20 \mu \mathrm{g} \mathrm{ml}^{-1}\right)$ than AZT-free sulfated laminaripentaose $\left(\mathrm{EC}_{50}=160 \mu \mathrm{g} \mathrm{ml}^{-1}\right)$ even when AZT was not released from sulfated laminaripentaose, and a low cytotoxicity of $\mathrm{CC}_{50}$ above $1000 \mu \mathrm{g} \mathrm{ml}^{-1}$. Moreover, an alkyl group combined to the reducing end of AZT-bound sulfated alkyl laminaripentaoside increased the anti-HIV activity further $\left(\mathrm{EC}_{50}=0.04-0.23 \mu \mathrm{g} \mathrm{ml}^{-1}\right)$. In addition, AZT-bound sulfated alkyl laminaripentaoside possessed a very low or undetectable anticoagulant activity.

KEY WORDS Oligosaccharide / Azidothymidine / Human Immunodeficiency Virus / Sulfation / Drug Delivery System /
\end{abstract}

Azidothymidine (AZT), which is an inhibitor of virus reverse transcriptase, was first approved to treat AIDS patients in $1987 .^{1,2}$ Since then, other several nucleoside analogues including 2', $3^{\prime}$-dideoxyinosine (DDI), 2', $3^{\prime}$ dideoxycytidine (DDC), 2', $3^{\prime}$-didehydrothymidine (D4T), and 2',3'-dideoxy-3'-thiacytidine (3TC) have been clinically used. ${ }^{3,4}$ Recently, a few protease inhibitors such as saquinavir (Ro31-8959), ritonavir (ABT-538) and indinavir (MK-639) have been clinically used for treatment of AIDS patients. ${ }^{5}$ Among these drugs, AZT is still one of the most effective drugs. Especially, a combined usage of $\mathrm{AZT}$, another reverse transcriptase inhibitor (DDC, or 3TC), and a protease inhibitor is so effective that, in many AIDS patients, viral load was reduced dramatically, and could not be detected in the blood cells even by the most sensitive test method after a period of therapy. ${ }^{6}$ However, pharmacokinetic studies of AZT in phase I trials have indicated that plasma half-life time of AZT is approximately $1 \mathrm{~h}^{7}$ Hence, frequent administration of excess AZT is necessary to maintain AZT therapeutic drug level in the blood, although AZT possesses serious side effects which are significant dose-related toxicities resulting in anenia and leucopenia. ${ }^{8,9}$ Therefore, an AZT prodrug with prolonged retention time in the blood might be desirable.

Since De Clerq suggested that polyanions such as dextran sulfate may suppress Human Immunodeficiency Virus (HIV) replication, ${ }^{10}$ various sulfated polysaccharides have been reported to exhibit anti-HIV activities in vitro. ${ }^{11-15}$ Most of them, such as heparin, and dextran sulfate possess a high anticoagulant activity that has been regarded as a serious side effect for AIDS

\footnotetext{
† To whom correspondence should be addressed.
}

patients. We have synthesized various sulfated polysaccharides. ${ }^{16-18}$ Curdlan sulfate exhibits desired bioactivities. Phase I/II clinical trial of the curdlan sulfate has been performed in the United States since 1992. The results have demonstrated that administration of the curdlan sulfate increases the number of CD4 lymphocytes in patients' blood. ${ }^{19}$ In addition, we have also synthesized various sulfated alkyl oligosaccharides with potent anti-HIV activities. ${ }^{20-22}$ Of these, sulfated dodecyl laminaripentaoside has exhibited not only a high anti-HIV activity and a low to almost no anticoagulant activity, but also prolonged retention time in animal body. ${ }^{23}$

In the present study, to synthesize novel AZT prodrugs with prolonged AZT retention time in the blood, AZT was bound to sulfated laminaripentaose and sulfated alkyl laminaripentaoside through biodegradable linkage. Synthesis of the AZT-bound sulfated laminaripentaose and AZT-bound sulfated alkyl laminaripentaosides was performed according to the synthetic route illustrated in Scheme 1. Anti-HIV and anticoagulant activities of AZT-bound sulfated laminaripentaose and AZT-bound sulfated alkyl laminaripentaosides in vitro were assayed.

\section{EXPERIMENTAL}

\section{Materials and General Method}

Commercial AZT was used as purchased. 4-Dimethylaminopyridine (DMAP), $N, N$-dicyclohexylcarbodiimide (DCC), sulfur trioxide-pyridine complex, potassium acetate, ferric chloride, acetic anhydride, and sodium methoxide were used without further purification. Pyridine and toluene were distilled before use. ${ }^{1} \mathrm{H}$ NMR spectra were recorded with a JEOL LA400 spec- 


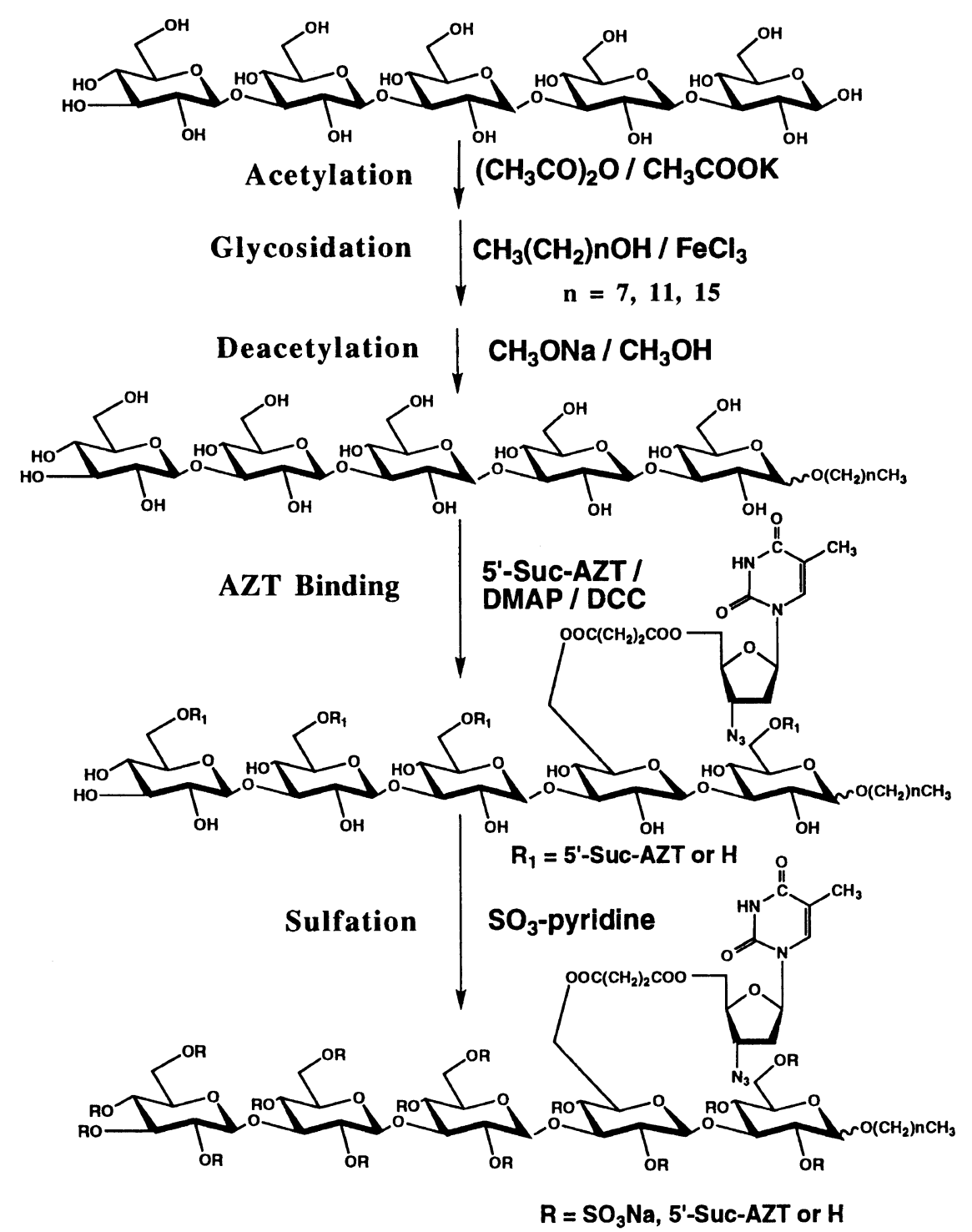

Scheme 1. Synthetic route of AZT-bound sulfated alkyl laminaripentaosides.

trometer working at $400 \mathrm{MHz}$. Sample was measured on $\mathrm{D}_{2} \mathrm{O}$ solution. AZT content in AZT-bound sulfated laminaripentaose was determined by UV spectroscopy by using the calibration curve based on mixtures of 5'-succinyl-AZT (5'-Suc-AZT) and sulfated oligosaccharide as references. Samples were measured in 0.1 $\mu \mathrm{g} \mathrm{ml}^{-1}$ aqueous solutions.

\section{Synthesis of Alkyl Laminaripentaoside}

Alkyl laminaripentaoside was synthesized according to the previously reported method with a few modifications. ${ }^{21,22}$

Ferric chloride $(0.35 \mathrm{~g}, 2.7 \mathrm{mmol})$ was added to peracetylated laminaripentaose $(1.3 \mathrm{~g}, 0.85 \mathrm{mmol})$ and dodecyl alcohol $(0.25 \mathrm{~g}, 1.34 \mathrm{mmol})$ solution in pyridine $(5 \mathrm{ml})$ at $55^{\circ} \mathrm{C}$ under nitrogen atmosphere. The reaction was monitored by thin layer chromatography (TLC). After the reaction was completed, the residue was purified by column chromatography over silica gel using mixtures of ethyl acetate and hexane $(7: 3,2: 1)$ as eluent. Peracetylated dodecyl laminaripentaoside was obtained in $47 \%$ yield.
Synthesis of 5'-Suc-AZT, AZT-Bound Laminaripentaose and AZT-Bound Alkyl Laminaripentaoside

5 -Suc-AZT was prepared in $78 \%$ yield by the reaction of AZT with succinic anhydride in the presence of DMAP as catalyst in pyridine at $0^{\circ} \mathrm{C} .{ }^{24}$

To a cetyl laminaripentaoside $(0.15 \mathrm{~g}, 0.14 \mathrm{mmol})$ solution in pyridine $(5 \mathrm{ml})$ were added 5 -Suc-AZT $(0.25 \mathrm{~g}, 0.68 \mathrm{mmol})$ and DMAP $(0.10 \mathrm{~g})$. Then, DCC $(0.20 \mathrm{~g})$ was added gradually to the above solution for $30 \mathrm{~min}$. The mixture was stirred for $5 \mathrm{~h}$ at room temperature. Then, hexane was poured until precipitates appeared. The precipitates were collected by centrifugation, followed by dialyzing overnight. A white powdery AZT-bound cetyl laminaripentaoside $(0.20 \mathrm{~g})$ was obtained by freeze-drying from water. Yield: $88 \%$.

AZT-bound laminaripentaose was also prepared according to the above procedure by using laminaripentaose instead of cetyl laminaripentaoside.

Synthesis of AZT-Bound Sulfated Laminaripentaose and AZT-Bound Sulfated Alkyl Laminaripentaoside

$\mathrm{SO}_{3}$-pyridine complex $(1.15 \mathrm{~g}, 7.2 \mathrm{mmol})$ was added to an AZT-bound dodecyl laminaripentaoside $(0.20 \mathrm{~g}$, 
$0.13 \mathrm{mmol})$ solution in pyridine $(5 \mathrm{ml})$. The mixture was stirred at $80^{\circ} \mathrm{C}$ for $75 \mathrm{~min}$. Then, it was neutralized by addition of a saturated $\mathrm{NaHCO}_{3}$ solution, followed by dialysis against deionized water overnight. The dialyzate was concentrated under a reduced pressure, and freeze-dried from water to give an AZT-bound sulfated dodecyl laminaripentaoside $(0.22 \mathrm{~g})$. Yield: $57 \%$.

\section{Anti-HIV Activity Assay}

Anti-HIV activities of the AZT-bound sulfated laminaripentaose and AZT-bound sulfated alkyl laminaripentaosides were assayed by use of the 3-(4,5-dimethylthiazol-2-yl)-2,5-diphenyltetrazolium (MTT) method. ${ }^{25}$ In the microplate test (96 wells), MT-4 cells were placed in each well at the rate of $2.5 \times 10^{4}$ cells $/$ well. The above cell culture was then infected by the addition of HIV-1 $1_{\text {HTLV-IIIB }}$ at the multiplicity of 0.01 in the presence of various concentrations of the test compound. Tests on mock-infected MT-4 cell were carried out in parallel to determine the cytotoxicity of the test compound. HIV-1- and mock-infected MT-4 cells were incubated for 5 days at $37^{\circ} \mathrm{C}$ in a $\mathrm{CO}_{2}$ incubator. Then, the cell suspension was collected and mixed with MTT. The viability of both HIV-1- and mock-infected cells was measured spectrophotometrically via the reduction of MTT. A $50 \%$ effective concentration $\mathrm{EC}_{50}$ was defined as a concentration of test compound which protects $50 \%$ cells from the virus infection. A $50 \%$ cytotoxic concentration $\left(\mathrm{CC}_{50}\right)$ was determined by a $50 \%$ cytotoxic concentration of the test compound in the MT-4 cell culture.

\section{Anticoagulant Activity Assay}

Anticoagulant activity was evaluated by a modification of the United States Pharmacopoeia method using bovine plasma. ${ }^{26}$ Dextran sulfate with an anticoagulant activity of 21.0 unit $\mathrm{mg}^{-1}$ was used as a reference.

\section{RESULTS AND DISCUSSION}

\section{Synthesis and Structure Analysis}

AZT-bound sulfated laminaripentaose and AZTbound sulfated alkyl laminaripentaosides were synthesized by a series of reactions as illustrated in Scheme 1.

Alkyl laminaripentaosides were prepared as reported previously with a few modifications. ${ }^{21,22}$ Peracetylated laminaripentaose was obtained in $90 \%$ yield by the reaction of laminaripentaose with acetic anhydride in the presence of potassium acetate as catalyst. The product contained $\beta$-configurated peracetylated laminaripentaoside desirable for the next glycosidation as high as $87 \%$, since potassium acetate as catalyst and high reaction temperature were employed.

Alkyl group was bound to the reducing end of the oligosaccharide by the reaction of peracetylated laminaripentaose with aliphatic alcohol by use of a strong Lewis acid $\mathrm{FeCl}_{3}$ as catalyst. Table I shows the result of glycosidations. It was revealed that alkyl peracetylated laminaripentaosides were obtained in $38-47 \%$ yields, and no degradation of the oligosaccharide was observed unless the reaction temperature exceeded $55^{\circ} \mathrm{C}$.

In the deacetylation step, alkyl laminaripentaosides were prepared in $95 \%$ yield by adding sodium methoxide into alkyl peracetylated laminaripentaoside solution in methanol, followed by stirring the solution for $5 \mathrm{~h}$.

AZT was bound to backbone of the oligosaccharide by esterification of laminaripentaose or alkyl laminaripentaoside with 5 -Suc-AZT by using DMAP and DCC in combination as catalyst in pyridine. Results are summarized in Table II. The degree of AZT substitution based on a glucose unit of oligosaccharide ranged from 0.2 to 0.4 , which was determined by ${ }^{1} \mathrm{H}$ NMR spectroscopy. It has been revealed that sulfated alkyl oligosaccharides must have degree of sulfation higher than 2.5 to exhibit a high anti-HIV activity. ${ }^{27}$ Since a glucose

Table I. Glycosidation of peracetylated laminaripentaose with aliphatic alcohol

\begin{tabular}{|c|c|c|c|c|c|c|c|}
\hline \multirow{2}{*}{ No. } & \multirow{2}{*}{$\frac{\text { Peracetylated L5 }}{\mathrm{g}(\mathrm{mmol})}$} & \multicolumn{2}{|c|}{ Aliphatic alcohol } & \multirow{2}{*}{$\frac{\text { Temp }}{{ }^{\circ} \mathrm{C}}$} & \multirow{2}{*}{$\frac{\mathrm{FeCl}_{3}}{\mathrm{~g}(\mathrm{mmol})}$} & \multirow{2}{*}{ Time } & \multirow{2}{*}{$\begin{array}{l}\text { Yield } \\
\%(g)\end{array}$} \\
\hline & & Length $^{\mathrm{b}}$ & $\mathrm{g}(\mathrm{mmol})$ & & & & \\
\hline 1 & $1.0(0.65)$ & 8 & $0.35(2.70)$ & 50 & $0.30(1.84)$ & 10 & $44(0.47)$ \\
\hline 2 & $1.3(0.85)$ & 12 & $0.25(1.34)$ & 55 & $0.35(2.15)$ & 40 & $47(0.68)$ \\
\hline 3 & $1.3(0.85)$ & 12 & $0.25(1.34)$ & 80 & $0.35(2.15)$ & 40 & trace \\
\hline 4 & $1.1(0.72)$ & 16 & $0.30(1.24)$ & 55 & $0.40(2.45)$ & 45 & $38(0.48)$ \\
\hline
\end{tabular}

${ }^{a}$ Peracetylated laminaripentaose. ${ }^{\mathrm{b}}$ Carbon number of aliphatic alcohol.

Table II. Reaction of laminaripentaose and alkyl laminaripentaoside with $5^{\prime}$-Suc-AZT ${ }^{\mathrm{a}}$

\begin{tabular}{|c|c|c|c|c|c|c|}
\hline \multirow{2}{*}{ No. } & \multicolumn{2}{|c|}{ Alkyl L5 } & \multirow{2}{*}{$\frac{5^{\prime}-\text { Suc-AZT }}{\mathrm{g}(\mathrm{mmol})}$} & \multirow{2}{*}{$\frac{\mathrm{DMAP} / \mathrm{DCC} \mathrm{d}^{\mathrm{d}}}{\mathrm{g} / \mathrm{g}}$} & \multirow{2}{*}{$\begin{array}{c}\text { Yield } \\
\text { g }(\%)\end{array}$} & \multirow{2}{*}{$\frac{\mathrm{DS}_{\mathrm{AZT}}^{\mathrm{e}}}{\mathrm{AZT} \text {-Bound }}$} \\
\hline & $\mathrm{g}(\mathrm{mmol})$ & Length $^{\mathrm{f}}$ & & & & \\
\hline 1 & $0.20(0.24)$ & 0 & $0.25(0.68)$ & $0.15 / 0.25$ & $0.11(38)$ & $0.20^{\mathrm{g}}$ \\
\hline 2 & $0.11(0.12)$ & 8 & $0.15(0.41)$ & $0.10 / 0.20$ & $0.10(50)$ & 0.42 \\
\hline 3 & $0.11(0.12)$ & 12 & $0.16(0.44)$ & $0.10 / 0.20$ & $0.13(72)$ & 0.35 \\
\hline 4 & $0.15(0.14)$ & 16 & $0.25(0.68)$ & $0.10 / 0.25$ & $0.20(88)$ & 0.31 \\
\hline
\end{tabular}

${ }^{a}$ Reacted in pyridine at room temperature for $5 \mathrm{~h}$. ${ }^{\mathrm{b}}$ Alkyl laminaripentaoside and laminaripentaose. ${ }^{\mathrm{c}} 5^{\prime}$-Succinyl-AZT. ${ }^{\mathrm{d}} 4$ Dimethylaminopyridine in combination with $N, N$-dicyclohexylcarbodiimide as catalyst. ${ }^{\mathrm{e}}$ Degree of AZT substitution to a glucose unit of oligosaccharide was determined by ${ }^{1} \mathrm{H}$ NMR. ${ }^{\mathrm{f}}$ Carbon number of alkyl group. ${ }^{\mathrm{g}}$ Determined by UV spectroscopy and elemental analysis after sulfation. 
Table III. Sulfation of AZT-bound laminaripentaose and AZT-bound alkyl laminaripentaosides

\begin{tabular}{|c|c|c|c|c|c|c|c|c|c|c|c|}
\hline \multirow{2}{*}{ No. } & \multicolumn{2}{|c|}{ AZT-L5C } & \multirow{2}{*}{$\frac{\mathrm{SO}_{3}-\mathrm{py}^{\mathrm{b}}}{\mathrm{g}(\mathrm{mmol})}$} & \multirow{2}{*}{$\begin{array}{c}\text { Yield } \\
\%\end{array}$} & \multicolumn{4}{|c|}{ Elemental analysis } & \multirow{2}{*}{$\mathrm{DSul}^{\mathrm{c}}$} & \multirow{2}{*}{$\mathrm{DS}_{\mathrm{AZT}}{ }^{\mathrm{d}}$} & \multirow{2}{*}[\alpha]{$_{\mathrm{D}}^{25 \mathrm{e}}$} \\
\hline & $\mathrm{g}(\mathrm{mmol})$ & $\begin{array}{l}\text { Alkyl }^{\mathrm{f}} \\
\text { group }\end{array}$ & & & \multicolumn{4}{|c|}{$\begin{array}{l}\text { Calcd } \\
\text { Found }\end{array}$} & & & \\
\hline 1 & $0.11(0.13)$ & 0 & $0.53(3.5)$ & 38 & $\begin{array}{l}18.5 \\
18.2\end{array}$ & $\begin{array}{l}2.53 \\
2.54\end{array}$ & $\begin{array}{l}2.57 \\
2.08\end{array}$ & $\begin{array}{l}17.6 \\
16.2\end{array}$ & 3.0 & $0.20^{\mathrm{g}}$ & +1.0 \\
\hline 2 & $0.10(0.06)$ & 8 & $0.40(2.5)$ & 34 & $\begin{array}{l}22.9 \\
21.7\end{array}$ & $\begin{array}{l}2.95 \\
2.95\end{array}$ & $\begin{array}{l}4.20 \\
3.74\end{array}$ & $\begin{array}{l}14.9 \\
13.0\end{array}$ & 3.1 & 0.42 & $-{ }^{h}$ \\
\hline 3 & $0.20(0.13)$ & 12 & $1.15(7.2)$ & 57 & $\begin{array}{l}25.4 \\
25.0\end{array}$ & $\begin{array}{l}3.34 \\
3.44\end{array}$ & $\begin{array}{l}3.52 \\
3.22\end{array}$ & $\begin{array}{l}15.0 \\
14.5\end{array}$ & 2.8 & 0.31 & -7.6 \\
\hline 4 & $0.25(0.17)$ & 16 & $1.25(7.8)$ & 58 & $\begin{array}{l}25.0 \\
24.4\end{array}$ & $\begin{array}{l}3.50 \\
3.51\end{array}$ & $\begin{array}{l}2.98 \\
2.67\end{array}$ & $\begin{array}{l}15.0 \\
14.7\end{array}$ & 2.9 & 0.29 & +2.4 \\
\hline
\end{tabular}

${ }^{a}$ AZT-bound laminaripentaose and AZT-bound alkyl laminaripentaoside. ${ }^{\mathrm{b}}$ Sulfur trioxide pyridine complex. ${ }^{\mathrm{c}}$ Degree of sulfation based on a glucose unit was determined by elemental analysis in combination with ${ }^{1} \mathrm{H}$ NMR. ${ }^{\mathrm{d}}$ Degree of AZT substitution based on a glucose unit was determined by ${ }^{1} \mathrm{H}$ NMR spectroscopy. ${ }^{\mathrm{e}}$ Specific rotation measured in $\mathrm{H}_{2} \mathrm{O}\left(\mathrm{c}=5 \mu \mathrm{g} \mathrm{mL}{ }^{-1}\right)$ in unit deg $\cdot \mathrm{dm}^{-1} \cdot \mathrm{g}^{-1} \cdot \mathrm{cm}^{3}$. ${ }^{\mathrm{f}} \mathrm{Carbon} \mathrm{number}$ of alkyl group. ${ }^{\mathrm{g}}$ Determined by UV spectroscopy and elemental analysis. ${ }^{\mathrm{h}}$ Not detected.

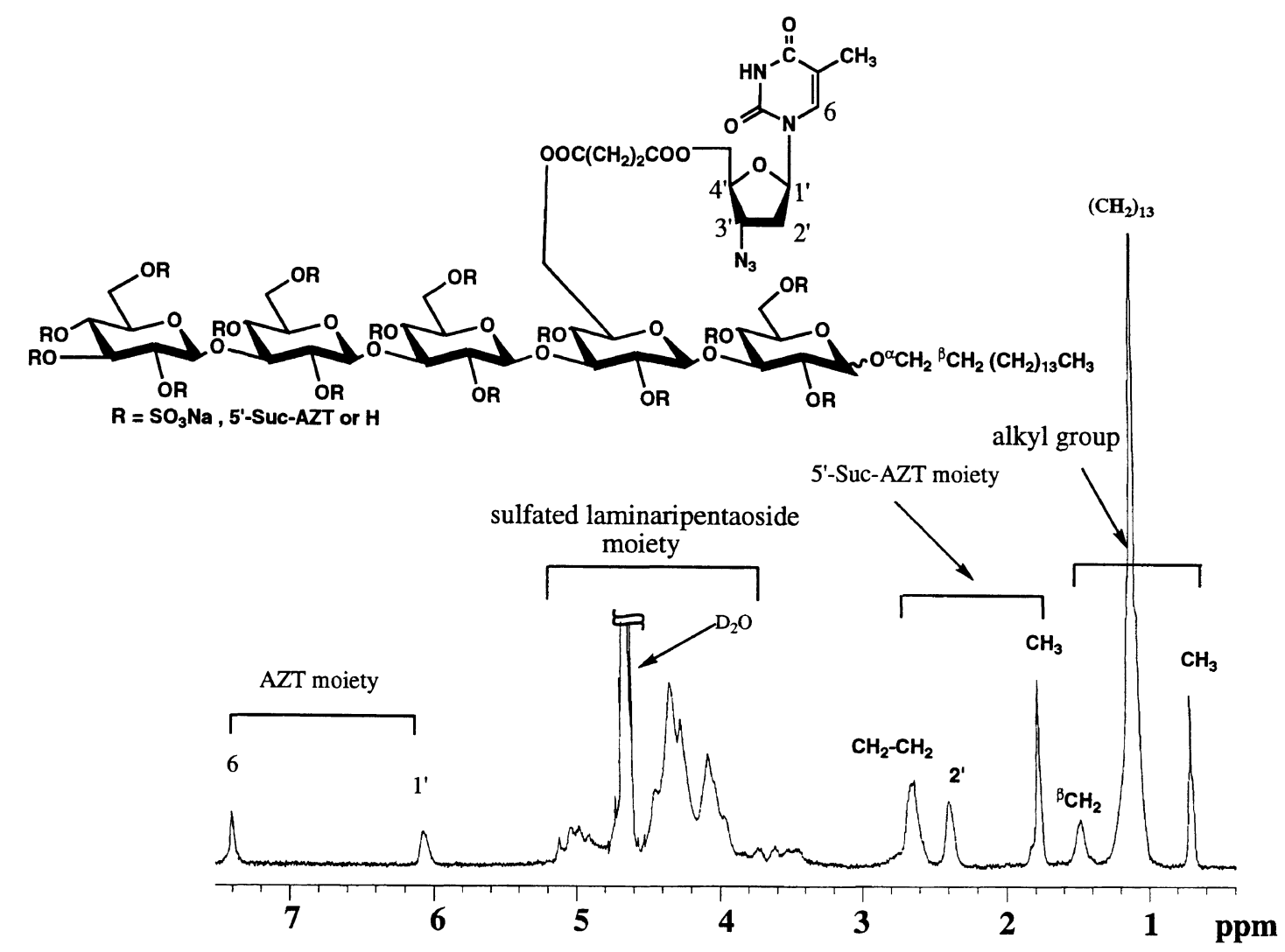

Figure 1. 400-MHz ${ }^{1} \mathrm{H}$ NMR spectrum of AZT-bound sulfated cetyl laminaripentaoside $\left(\mathrm{D}_{2} \mathrm{O}\right.$ as a solvent at $\left.25^{\circ} \mathrm{C}\right)$.

unit in alkyl laminaripentaoside has 3.2 potential hydroxyl groups on average to be substituted by AZT and sulfate group, the degree of AZT substitution less than 0.7 seems desirable to obtain an AZT-bound sulfated alkyl laminaripentaoside with degree of sulfation of more than 2.5. In addition, it was also observed that 5'-Suc-AZT ester moiety increased the hydrophobicity of laminaripentaose and alkyl laminaripentaoside.

AZT-bound laminaripentaose and AZT-bound alkyl laminaripentaosides were sulfated with $\mathrm{SO}_{3}$-pyridine complex to give the corresponding sulfates. Table III summarizes results. The degree of AZT substitution $\left(\mathrm{DS}_{\mathrm{AZT}}\right)$ ranged from 0.2 to 0.4 , and did not change by sulfation, indicating that AZT was not severed from the AZT-carbohydrate during the sulfation. Sulfur content in the AZT-bound sulfated laminaripentaose and AZT-bound sulfated alkyl laminaripentaosides was in the range of 13.0 to $16.2 \%$, and the degree of sulfation based on a glucose unit of oligosaccharide was from 2.8 to 3.1. As mentioned above, the maximum degree substituted by AZT and sulfate group is about 3.2. For the compound (No. 2), the total substituted degree $\left(\mathrm{DS}_{\mathrm{AZT}}+\mathrm{DSul}=3.5\right)$ was higher than the maximum theoretical data (3.2), that may be due to sodium sulfate involved in the compound even after dialysis. This phenomenon was also observed in the previous works. $^{21,22}$ 
Table IV. Anti-HIV and anticoagulant activities of AZT-bound sulfated laminaripentaose and AZT-bound sulfated alkyl laminaripentaosides

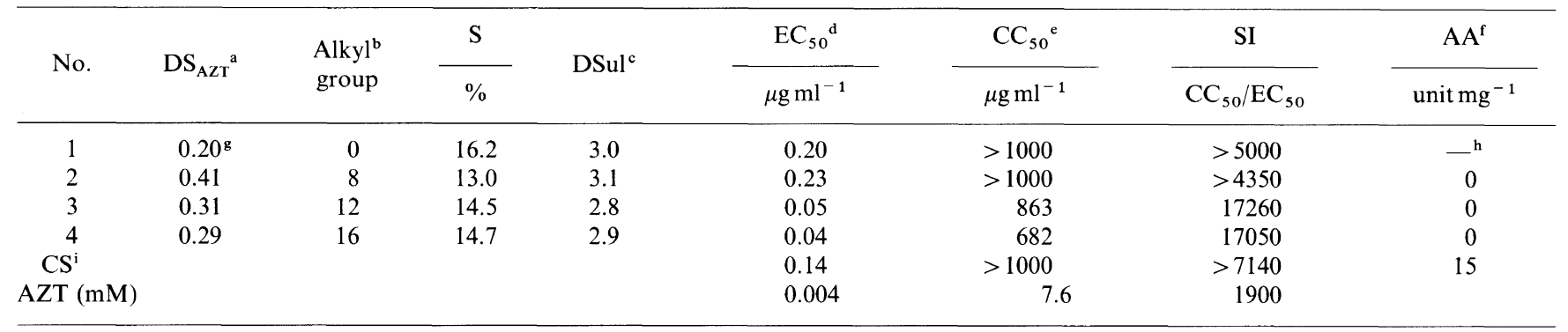

${ }^{a}$ Degree of AZT substitution was determined by ${ }^{1} \mathrm{H}$ NMR spectroscopy. ${ }^{\mathrm{b}}$ Carbon number of alkly group. ${ }^{\mathrm{c}}$ Degree of sulfation based on a glucose unit. ${ }^{\mathrm{d}}$ Anti-HIV activity: Drug concentration effective for 50\% inhibition of virus infection in 5-day HIV-infected MT-4 cell culture. ${ }^{\mathrm{e}}$ Cytotoxic effect: Drug concentration $50 \%$ cytotoxicity in 5-day MT-4 cell culture. ${ }^{\mathrm{f}}$ Anticoagulant activity: Commercial dextran sulfate having

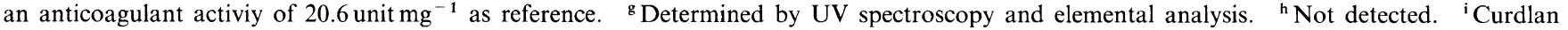
sulfate having weight average molecular weight of $7.9 \times 10^{4}$ as reference.

Structure of the AZT-bound sulfated alkyl laminaripentaoside was analyzed by ${ }^{1} \mathrm{H}$ NMR spectroscopy, as shown in Figure 1. Assignment of peaks was identified according to spectra of $5^{\prime}$-Suc-AZT and sulfated alkyl laminaripentaoside.

\section{Anti-HIV and Anticoagulant Activities}

Anti-HIV activities of the AZT-bound sulfated laminaripentaose and AZT-bound sulfated alkyl laminaripentaosides were assayed by use of the MTT method in vitro. ${ }^{25}$ Since sulfated laminaripentaose or sulfated alkyl laminaripentaoside is not only an AZT carrier but also an anti-HIV agent in the prodrug, the prodrug itself possesses an anti-HIV activity even when AZT is not released. Moreover, it has been reported that ester bond binding AZT with carrier was stable under a moderate $\mathrm{pH}$ condition in vitro, ${ }^{28}$ and AZT is not released from the carrier. ${ }^{24}$ Therefore, it is assumed that activity detected by the MTT method represents that of the prodrug itself, the activity from free AZT can not be added to the activity detected by the MTT in vitro.

Results of anti-HIV activities of the AZT-bound sulfated laminaripentaose and AZT-bound sulfated alkyl laminaripentaosides are summarized in Table IV. For AZT-bound sulfated laminaripentaose even without terminal alkyl group, the activity represented by $\mathrm{EC}_{50}=$ $0.20 \mu \mathrm{g} \mathrm{ml}^{-1}$ was very high. However, the anti-HIV activity of AZT-free sulfated laminaripentaose, i.e., $\mathrm{EC}_{50}=160 \mu \mathrm{g} \mathrm{ml}^{-1}$, was low. ${ }^{21}$ The high anti-HIV activity may be due to introduction of $5^{\prime}$-Suc-AZT ester moiety which increased the hydrophobicity of sulfated laminaripentaose, but not due to the release of AZT since released AZT must show its high cytotoxicity. While the AZT-bound sulfated laminaripentaose exhibited a low cytotoxicity represented by $\mathrm{CC}_{50}$ value larger than $1000 \mu \mathrm{g} \mathrm{ml}^{-1}$. AZT-bound sulfated alkyl laminaripentaosides in which a long alkyl group was combined to the reducing terminal of the laminaripentaose exhibited very high anti-HIV activities of $\mathrm{EC}_{50}$ ranging from 0.04 to $0.23 \mu \mathrm{g} \mathrm{ml}^{-1}$. The introduction of $5^{\prime}$ Suc-AZT ester moiety enhanced also anti-HIV activities of sulfated alkyl laminaripentaoside, i.e., $\mathrm{EC}_{50}=$ $0.05 \mu \mathrm{g} \mathrm{ml}^{-1}$ for AZT-bound sulfated dodecyl laminaripentaoside (Table IV), and $\mathrm{EC}_{50}=0.20 \mu \mathrm{g} \mathrm{ml}^{-1}$ for AZT-free sulfated dodecyl laminaripentaoside. ${ }^{21}$ However, a slight cytotoxicity was observed for the compounds containing the alkyl group longer than dode- cyl group. The cytotoxicity increased with increasing length of alkyl group, but it was not affected by the degree of AZT substitution.

As mentioned above, sulfated laminaripentaose and sulfated alkyl laminaripentaosides exhibited high antiHIV activity by binding $5^{\prime}$-Suc-AZT ester to backbone of oligosaccharide. It has been revealed that introduction of a hydrophobic moiety into cyclodextrin sulfate led to an increase in anti-HIV activity. ${ }^{13}$ Therefore, it may be suggested that a hydrophobic moiety introduced into sulfated oligosaccharide with a medium molecular weight plays an important role in enhancing an anti-HIV activity. In addition, we have synthesized AZT-bound curdlan sulfate in order to delivery AZT into lymphatic tissue where replication of HIV is active. The introduction of $5^{\prime}$-Suc-AZT ester moiety did not enhanced the anti-HIV activity of curdlan sulfate. ${ }^{24}$ These findings hinted further that mechanism of the inhibitory effect of sulfated oligosaccharide on HIV infection may be different from that of sulfated polysaccharide.

Since an anticoagulant activity possessed by most sulfated polysaccharides is regarded as a serious side effect for AIDS patients, effectiveness of many sulfated polysaccharides in vivo has not been clarified. Therefore, anticoagulant activities of AZT-bound sulfated alkyl laminaripentaosides were estimated. AZT-bound sulfated alkyl laminaripentaosides exhibited almost no anticoagulant activity, as also shown in Table IV.

AZT-bound sulfated laminaripentaose and AZTbound sulfated alkyl laminaripentaosides exhibited not only high anti-HIV activity but also very low to undetectable anticoagulant activity. Therefore, they are promising candidates for further evaluation of therapy of HIV infection. Studies on the release of AZT from the carrier by an enzymatic hydrolysis and the antiHIV activity of the released AZT are in progress. Relationship between chemical structure of AZT-bound sulfated oligosaccharide and AZT retention time in blood after administering the AZT-bound sulfated oligosaccharide to animals will be also done.

\section{REFERENCES}

1. H. Mitsuya, K. J. Weinhole, P. A. Furman, M. H. St Clair, S. N. Lehrman, R. C. Gallo, D. Bolognesi, D. W. Barry, and S. Broder, Proc. Natl. Acad. Sci. U.S.A., 82, 7096 (1985).

2. H. Mitsuya, Proc. Natl. Acad. Sci. U.S.A., 84, 2033 (1987). 
3. H. Mitsuya and S. Broder, Proc. Natl. Acad. Sci. U.S.A., 83, 1911 (1986).

4. B. A. Larder, S. D. Kemp, and P. R. Harrigan, Science, 269, 696 (1995).

5. a) X. Wei, S. K. Ghosh, M. E. Taylor, V. A. Johnson, E. A. Emini, P. Deutsch, J. D. Lifson, S. Bonhoeffer, M. A. Nowak, B. H. Hahn, M. S. Saag, and G. M. Shaw, Nature, 373, 117 (1995); b) D. D. Ho, A. U. Neumann, A. S. Perelson, W. Chen, J. M. Leonard, and M. Markowitz, Nature, 373, 123 (1995).

6. C. Tamalet, A. Lafeuillade, J. Fantini, C. Poggi, and N. Yahi, AIDS, 11, 895 (1997).

7. R. W. Klecker, J. M. Collins, R. Yarchoan, R. Thoma, J. F. Jenkins, S. Broder, and C. E. Meyers, Clin. Pharmacol. Ther., 41, 407 (1987).

8. M. A. Fischl, D. D. Richman, M. H. Grieco, M. S. Gottlieb, P. A. Volberding, O. L. Laskin, J. M. Leedom, J. E. Groopman, D. Mildvan, R. T. Schooley, G. G. Jackson, D. T. Durack, and D. King, New Engl. J. Med., 317, 185 (1987).

9. D. D. Richman, M. A. Fischl, M. H. Grieco, M. S. Gottlieb, P A. Volberding, O. L. Laskin, J. M. Leedom, J. E. Groopman, D. Mildvan, M. S. Hirsch, G. G. Jackson, D. T. Durack, and S. Nusinoff-Lehrman, New Engl. J. Med., 317, 192 (1987).

10. E. De Clercq, J. Med. Chem., 29, 1561 (1986).

11. M. Baba, D. Schols, R. Pauwels, H. Nakashima, E. and De Clercq, J. Acquired Immunodeficiency Syndromes, 3, 493 (1990),

12. M. Holodniy, S. Kim, D. Katzenstein, M. Konrad, E. Groves, and T. C. Merigan, J. Clin. Microbiol., 29, 676 (1991).

13. T. Moriya, H. Kurita, K. Matsumoto, T. Otake, H. Mori, M. Morimoto, N. Ueba, and N. Kunita, J. Med. Chem., 34, 2301 (1991).

14. E. Mbemba, V. Chams, J. C. Gluckman, D. Klatzmann, and L. Gattegno, Biochim. Biophys. Acta, 1138, 62 (1992).

15. J. Neyts, D. Reymen, D. Letourneur, J. Jozefonvicz, D. Schols, J. Este, G Andrei, P. McKenna, M. Witvrouw, S. Ikeda, J.
Clement, and E. De Clercq, Biochem. Pharmacol., 50, 743 (1995).

16. K. Hatanaka, T. Yoshida, T. Uryu, O. Yoshida, H. Nakashima, N. Yamamoto, T. Mimura, and Y. Kaneko, Jpn. J. Cancer Res., 80, 95 (1989).

17. Y. Kaneko, O. Yoshida, R. Nakagawa, T. Yoshida, M. Date, S. Ogihara, T. Shioya, Y. Matsuzawa, H. Shinkai, N. Yasuda, K. Matsuzaki, T. Uryu, and N. Yamamoto, Biochem. Pharmacol., 25, 163 (1990).

18. T. Yoshida, K. Hatanaka, T. Uryu, Y. Kaneko, E. Suzuki, H. Miyano, T. Mimura, O. Yoshida, and N. Yamamoto, Macromolecules, 23, 3717 (1990).

19. M. Gordon, M. Guralnik, Y. Kaneko, T. Mimura, M. Baker, and W. Lang, J. Med., 25, 163 (1994).

20. T. Uryu, N. Ikushima, K. Katsuraya, T. Shoji, N. Takahashi, T. Yoshida, K. Kanno, T. Murakami, H. Nakashima, and N. Yamamoto, Biochem. Pharmacol., 43, 2385 (1992).

21. K. Katsuraya, N. Ikushima, N. Takahashi, T. Shoji, H. Nakashima, N. Yamamoto, T. Yoshida, and T. Uryu, Carbonhydr. Res., 260, 51 (1994).

22. K. Katsuraya, T. Shoji, K. Inazawa, H. Nakashima, N. Yamamoto, and T. Uryu, Macromolecules, 27, 6695 (1994).

23. H. Nakashima, K. Inazawa, K. Ichiyama, M. Ito, N. Ikushima, T. Shoji, K. Katsuraya, T. Uryu, N. Yamamoto, A. S. Juodawlkis, and R. F. Schinazi, Antiviral Chem. Chemother., 6, 271 (1995).

24. Y. Gao, K. Katsuraya, Y. Kaneko, T. Mimura, H. Nakashima, and T. Uryu, Polym. J., 30, 31 (1998).

25. R. Pauwels, J. Balzarini, M. Baba, R. Snoeck, D. Schols, P. Herdewijn, J. Desmyter, and E. De Clercq, J. Virol. Methods, 20, 309 (1988)

26. K. Hatanaka, T. Yoshida, S. Miyahara, T. Sato, F. Ono, T. Uryu, and H. Kuzuhara, J. Med. Chem., 30, 810 (1987).

27. K. Katsuraya and T. Uryu, to be submitted.

28. T. Kawaguchi, K. Ishikawa, T. Seki, and K. Juni, J. Pharm. Sci., 79, 531 (1990) 